\title{
Subcellular Localization of Tetanus Neurotoxin-Insensitive Vesicle- Associated Membrane Protein (VAMP)/VAMP7 in Neuronal Cells: Evidence for a Novel Membrane Compartment
}

\author{
Silvia Coco, ${ }^{2}$ Graca Raposo,, ${ }^{1}$ Sonia Martinez, ${ }^{1}$ Jean-Jacques Fontaine, ${ }^{4}$ Shigeo Takamori, ${ }^{3}$ \\ Ahmed Zahraoui,, ${ }^{1}$ Reinhard Jahn, ${ }^{3}$ Michela Matteoli, ${ }^{2}$ Daniel Louvard,, ${ }^{1}$ and Thierry Galli ${ }^{1}$ \\ ${ }^{1}$ Centre National de la Recherche Scientifique, Unité Mixte de Recherche 144, Compartimentation et Dynamique \\ Cellulaires, Institut Curie, F-75248 Paris CEDEX 05, France, ${ }^{2}$ Consiglio Nazionale delle Ricerche, Center of Cellular and \\ Molecular Pharmacology and B. Ceccarelli Center, 20129 Milano, Italy, ${ }^{3}$ Department of Neurobiology, Max-Planck- \\ Institute for Biophysical Chemistry, Am Faßberg, D-37077 Göttingen, Germany, and ${ }^{4}$ Laboratoire d'Anatomie \\ Pathologique, Ecole Vétérinaire d'Alfort, F-94704 Maisons Alfort CEDEX, France
}

The clostridial neurotoxin-insensitive soluble $N$-ethylmaleimidesensitive factor attachment protein (SNAP) receptors, tetanus neurotoxin-insensitive ( $\mathrm{TI}$ )-vesicle-associated membrane protein (VAMP)/VAMP7, SNAP23, and syntaxin 3 have recently been implicated in transport of exocytotic vesicles to the apical plasma membrane of epithelial cells. This pathway had been shown previously to be insensitive to tetanus neurotoxin and botulinum neurotoxin F. TI-VAMPNAMP7 is also a good candidate to be implicated in an exocytotic pathway involved in neurite outgrowth because tetanus neurotoxin does not inhibit this process in conditions in which it abolishes neurotransmitter release. We have now found that TI-VAMPNAMP7 has a widespread distribution in the adult rat brain in which its localization strikingly differs from that of nerve terminal markers. TI-VAMP/ VAMP7 does not enrich in synaptic vesicles nor in large dense-

Recent work on the molecular mechanism of membrane fusion led to a model in which soluble $N$-ethylmaleimide-sensitive factor attachment protein (SNAP) receptors (SNAREs) are necessary for this process (for review, see Johannes and Galli 1998; Jahn and Südhof, 1999). Membrane proteins located in a donor membrane (vesicular or v-SNAREs) form a stable complex (so called SNARE complex) with membrane proteins in a target compartment (t-SNAREs), a process resulting in lipid bilayer fusion (Weber et al., 1998). v-SNAREs include the vesicle-associated membrane protein (VAMP)/brevin protein family, and t-SNAREs include both the syntaxin and the synaptosomeassociated protein (SNAP23/25/29) family.

A main argument in favor of a major role of SNAREs in membrane fusion resides in the fact that clostridial neurotoxins (NT), the most potent blockers of neurotransmitter release, proteolytically cleave SNAP25, syntaxin 1 , or synaptobrevin $1 / 2$ in

\footnotetext{
Received June 30, 1999; revised Aug. 27, 1999; accepted Sept. 1, 1999.

This work was supported in part by Association pour la Recherche contre le Cancer Grant 9923 to A.Z., Telethon Italia Grant 1042, and European Community Grant BIO4-CT98-0408 to M.M. We dedicate this article to the memory of Heiner Niemann. We are indebted to Sylvie Manin for immunolabeling of paraffin sections, Claudia Verderio for initiating some experiments, Ahmed El Marjou and Lucien Cabanié for purification of antibodies, Dominique Morineau for excellent photographic service, and Margaret Butler for critical reading of this manuscript.

Correspondence should be addressed to Dr T. Galli, Centre National de la Recherche Scientifique, Unité Mixte de Recherche 144, Institut Curie, 26 rue d'Ulm, F-75248 Paris CEDEX 05, France. E-mail: thierry.galli@curie.fr.

Copyright (C) 1999 Society for Neuroscience $\quad 0270-6474 / 99 / 199803-10 \$ 05.00 / 0$
}

core granules but is associated with light membranes. In hippocampal neurons developing in vitro, TI-VAMP/VAMP7 localizes to vesicles in the axonal and dendritic outgrowths and concentrates into the leading edge of the growth cone, a region devoid of synaptobrevin 2, before synaptogenesis. After the onset of synaptogenesis, TI-VAMPNAMP7 is found predominantly in the somatodendritic domain. In PC12 cells, TI-VAMP/ VAMP7 does not colocalize with synaptobrevin 2, chromogranin B, or several markers of endocytic compartments. At the electron microscopic level, TI-VAMPNAMP7 is mainly associated with tubules and vesicles. Altogether, these results suggest that TI-VAMPNAMP7 defines a novel membrane compartment in neurite outgrowths and in the somatodendritic domain.

Key words: exocytosis; clostridial neurotoxin; neurite outgrowth; SNARE; TI-VAMP/VAMP7; synaptobrevin 2 neurons (for review, see Hay and Scheller, 1997; Edwardson, 1998; Johannes and Galli, 1998). Nevertheless, several exocytotic pathways have been found to partially or entirely resist NT treatment. In non-neuronal cells and in neuronal cells, NTs have partial effects on vesicular transport events (Galli et al., 1994; Regazzi et al., 1995; Fassio et al., 1999). In epithelial cells, Ikonen et al. (1995) showed that apical transport of influenza hemagglutinin is not sensitive to tetanus neurotoxin (TeNT) and that basolateral transport of vesicular stomatitis virus G-protein is only partially affected. In neurons developing in culture, it was shown that axonal and dendritic outgrowths are not affected by TeNT in conditions in which secretion is blocked (Chapron et al., 1991; OsenSand et al., 1996). Interestingly, botulinum neurotoxins (BoNTs) A and $\mathrm{C} 1$ are potent inhibitors of these pathways (Igarashi et al., 1996; OsenSand et al., 1996), suggesting the involvement of SNAP25 and/or syntaxin 1, t-SNAREs that are located in the plasma membrane of both axons and dendrites (Galli et al., 1995). On the contrary, BoNT A does not block giant miniature end plate potentials at the neuromuscular junction (Sellin et al., 1996). The occurrence of NT-resistant pathways in neurons and in non-neuronal cells indicates either the existence of SNARE-independent fusion mechanisms (Ikonen et al., 1995; Simons and Ikonen, 1997) or the presence of NT-resistant SNAREs. There is evidence for the latter possibility as demonstrated by the identification of TeNT-insensitive VAMP (TIVAMP) (Galli et al., 1998), also called VAMP7 (Bock and 

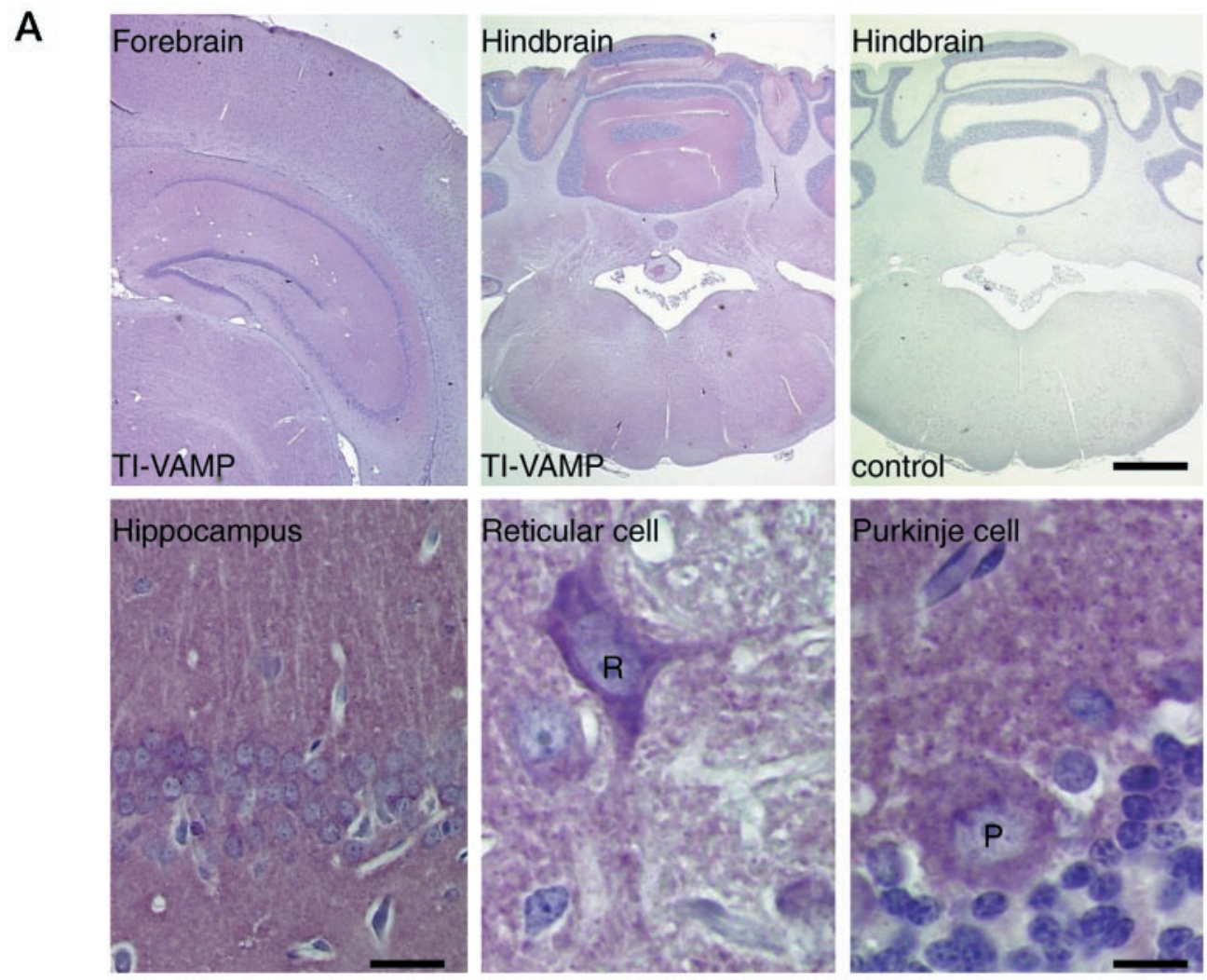

Figure 1. A widespread distribution of TI-VAMP/VAMP7 in the rat brain. Rat brain paraffin sections were stained for TI-VAMP/VAMP7 and slightly counterstained with hematoxylin (blue staining of nuclei). (Control slides were obtained on serial sections by omitting the first antibody.) Digital pictures were obtained on a DMR HC microscope (Leica) equipped with a tri-CCD color video camera Power HAD (Sony). [Scale bars: top left, $600 \mu \mathrm{m}$; top middle, top right, $200 \mu \mathrm{m}$; bottom left (hippocampus CA1 region), $30 \mu \mathrm{m}$; bottom middle, bottom right (reticular and Purkinje cells), $10 \mu \mathrm{m}$.] TI-VAMP/VAMP7 is present in most neurons. It is concentrated in cell bodies. $B$, TI-VAMP/ VAMP7 does not localize in nerve terminals in reticular cells. Double immunofluorescence confocal images showing the lack of colocalization of TI-VAMP/VAMP7 and SV2, an SV protein in the deep nuclei of the cerebellum. Scale bar, $25 \mu \mathrm{m}$.
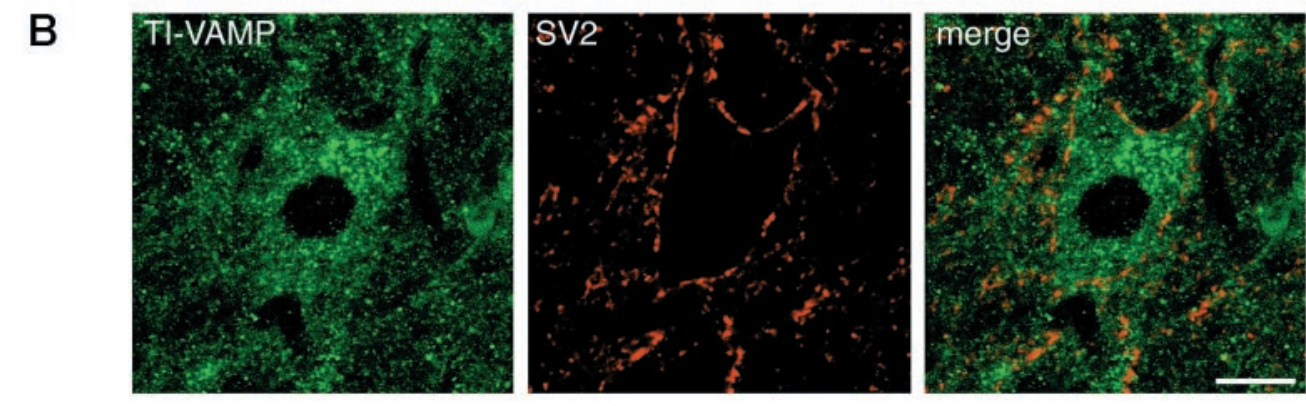

Scheller, 1997). TI-VAMP/VAMP7 is the product of synaptobrevin-like gene 1 , which is located on the pseudoautosomal region of Xq28 and undergoes X inactivation (D'Esposito et al., 1996). In contrast to synaptobrevin and cellubrevin, this new member of the v-SNARE family is neither cleaved by TeNT nor BoNT B, D, F, and G. Moreover, we were able to show that, in vivo, TI-VAMP/VAMP7 forms SNARE complexes with SNAP23 and syntaxin 3, a t-SNARE located exclusively at the apical plasma membrane of $\mathrm{CaCo}-2$ epithelial cells. These results suggested that TI-VAMP/VAMP7 could mediate one or several NT-resistant exocytotic pathways to the apical plasma membrane (Galli et al., 1998). Indeed, we have recently demonstrated that TI-VAMP/VAMP7 was present in apical vesicular structures in Madin-Darby canine kidney (MDCK) cells and was involved, together with syntaxin 3 and SNAP23, in apical transport of the influenza viral protein hemmaglutinin (HA). Interestingly, TIVAMP/VAMP7 and syntaxin 3 were found to be raft-associated (Lafont et al., 1999). Altogether, these results suggest that TIVAMP/VAMP7 is involved in apical delivery of raft-associated proteins and lipids in epithelial cells. These data allowed us to reconcile the finding that apical transport is insensitive to clostridial NTs (Ikonen et al., 1995), with the overwhelming evidence that suggests that SNAREs are in the heart of all membrane fusion machineries.

Distinct SNAREs are located in different intracellular compartments connected by membrane trafficking. Recent data indicate that SNARE complex formation in vitro is promiscuous (Von Mollard et al., 1997; Yang et al., 1999) and does not account for the specificity of the membrane fusion events seen in vivo after mutations in SNAREs in yeast and invertebrates (for review, see Johannes and Galli, 1998; Jahn and Südhof, 1999). It was shown recently that TI-VAMP/VAMP7 and endobrevin/VAMP8 form the same SNARE complexes as synaptobrevin 2 in vitro (Fasshauer et al., 1999; Yang et al., 1999). Indeed, TI-VAMP/ VAMP7 SNARE motif (Jahn and Sudhof, 1999) is highly similar to the one of synaptobrevin 2 (Galli et al., 1998). The key hydrophobic residues are identical together with the $\mathrm{R}$ residue located in the middle of the coiled coil and which, in the case of 
A

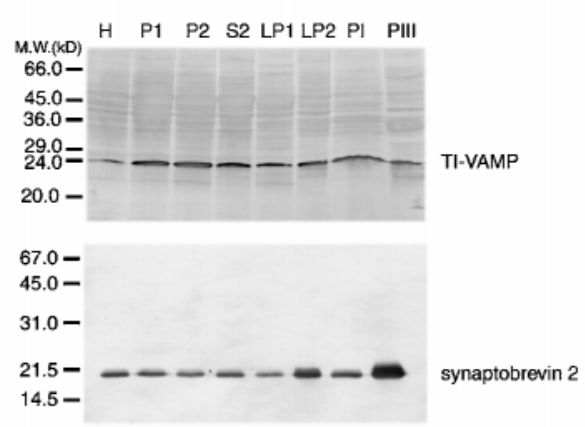

B

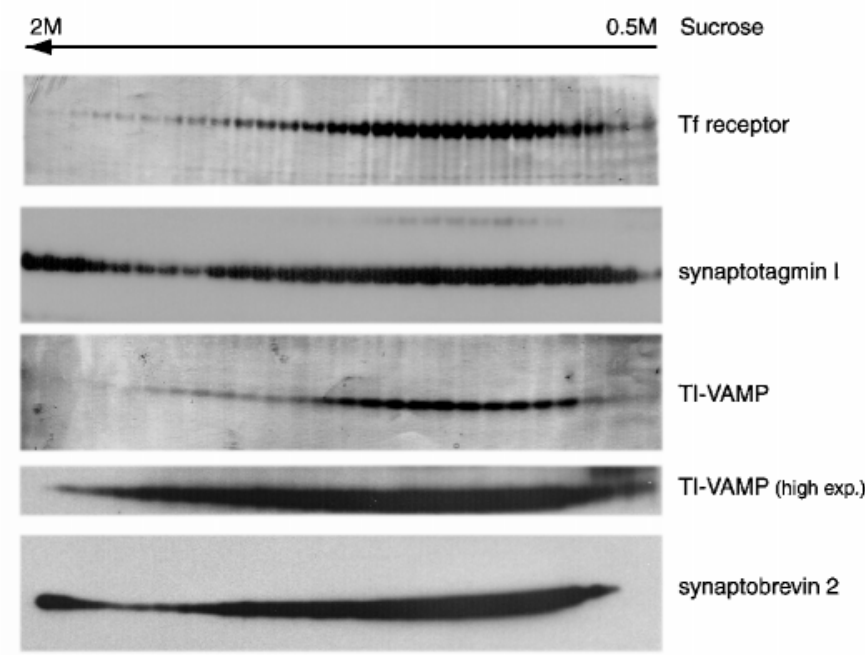

Figure 2. A TI-VAMP/VAMP7 is not a typical SV protein. Brain synaptic vesicles were prepared according to the procedure of Hell and Jahn (1994). The fractions are as follows. H, Homogenate; P1, $1000 \mathrm{gm}$ pellet; $P 2$, synaptosomal fraction, 12,000 gm pellet; $S 2$, microsomes and cytosol, 12,000 gm supernatant; $L P 1,33,000 \mathrm{gm}$ pellet of lysed synaptosomes; $L P 2$, crude SV fraction, 260,000 gm pellet of lysed synaptosomes; $P I$, controlled pore glass fraction corresponding mostly to plasma membrane and microsomes; PIII, controlled pore glass purified SVs. Twenty micrograms of proteins were loaded in each lane. Note that synaptobrevin 2 enriches greatly in LP2 and PIII fractions, whereas TI-VAMP/VAMP7 does not enrich in these fractions. $B$, TI-VAMP/VAMP7 does not enrich in large dense core vesicles. Distribution of secretory vesicle markers from a low-speed supernatant of bovine adrenal medulla homogenate by isopycnic centrifugation on a $0.4-2 \mathrm{M}$ sucrose gradient. Equal volumes of gradient fractions were analyzed by SDS-PAGE and Western blotting for the proteins indicated. Note that TI-VAMP/VAMP7 is not found in the membrane fractions at the bottom of the gradient in which synaptotagmin 1 and synaptobrevin 2 concentrates. TI-VAMP/VAMP7 and transferrin receptor are mainly concentrated in light fractions. A high exposure of the autoradiogram reveals a low concentration of TI-VAMP/VAMP7 in the heavy fractions corresponding to LDCVs.

synaptobrevin 2, forms a salt bridge with Q residues in syntaxin 1 and SNAP25 (Fasshauer et al., 1998; Galli et al., 1998). Because the SNARE motifs of synaptobrevin 2 and cellubrevin have also been found to mediate sorting to synaptic-like microvesicles in PC12 cells (Grote et al., 1995), it could be hypothesized that TI-VAMP/VAMP7 and synaptobrevin 2 should have a similar sorting if expressed in the same cells. Therefore, according to the "SNARE promiscuity" hypothesis, TI-VAMP/VAMP7 would be expected to have the capacity to replace synaptobrevin 2. In this
A
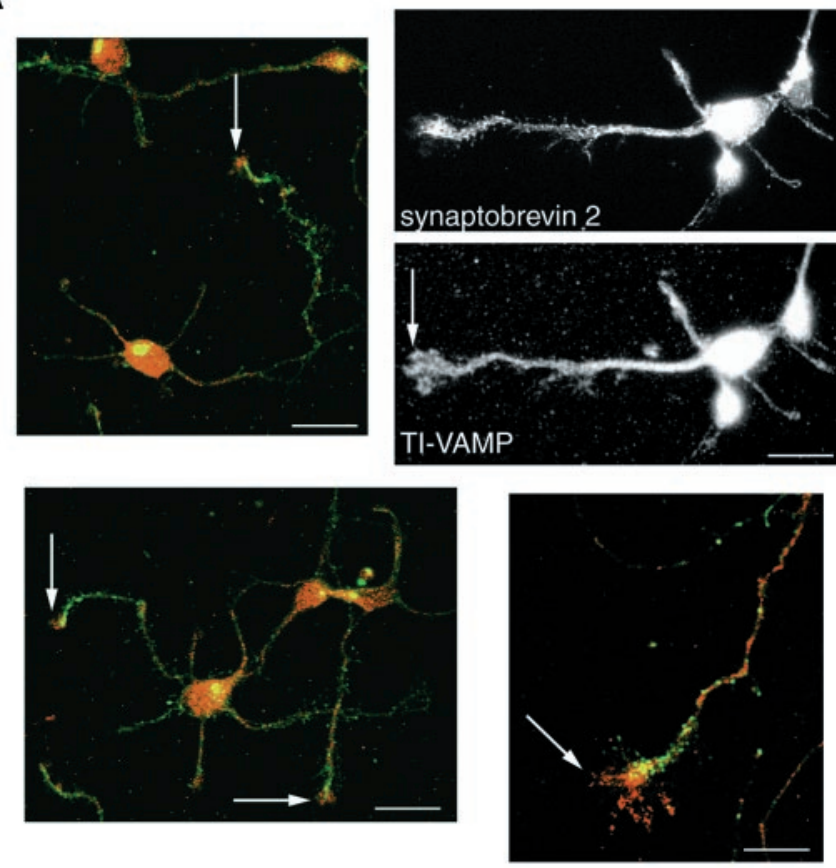

B

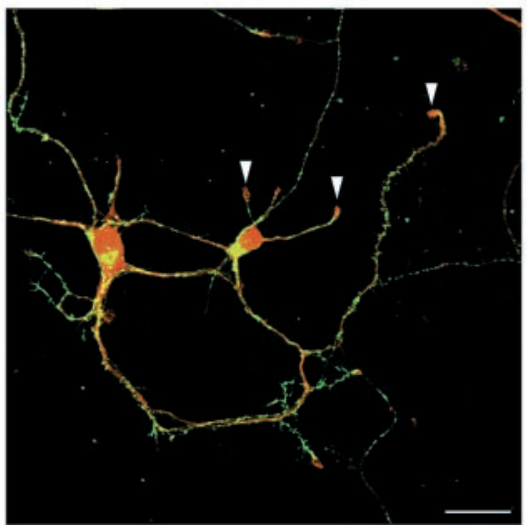

Figure 3. Localization of TI-VAMP/VAMP7 in axonal and dendritic outgrowths. $A$, TI-VAMP/VAMP7 in axonal outgrowths at 2 div. Rat hippocampal neurons in primary culture were fixed, stained at 2 div for TI-VAMP/VAMP7 (red) and synaptobrevin 2 ( green), and observed by confocal microcopy (color plates) or conventional microscopy (black and white plates). TI-VAMP/VAMP7 localized to vesicles scattered throughout the cell body, the neurites, and the growing axon. A significant amount of the protein was found at the leading edge of the growing axon (arrows) in which synaptobrevin 2 was not found. Distinct hot spots of TI-VAMP/VAMP7 and synaptobrevin 2 were observed along the axon. Very high concentrations of both proteins were found in the cell bodies. Scale bars: left color micrograph, $25 \mu \mathrm{m}$; right color micrograph, $10 \mu \mathrm{m}$; black and white micrographs, $12 \mu \mathrm{m}$. B, TI-VAMP/VAMP7 in dendritic outgrowths at 7 div. Rat hippocampal neurons in primary culture were fixed, stained at 7 div for TI-VAMP/VAMP7 (red) and synaptobrevin 2 ( green), and observed by confocal microcopy. Synaptobrevin 2 was found mainly in nerve terminals, whereas most of TI-VAMP/VAMP7 was localized in dendrites and concentrated in the leading edge of dendrites. Scale bar, $25 \mu \mathrm{m}$.

paper, we have performed a detailed biochemical and immunocytochemical analysis of TI-VAMP/VAMP7 in neuronal cells and compared it with synaptobrevin 2. Our main goal was to study whether TI-VAMP/VAMP7 was targeted to the same compart- 

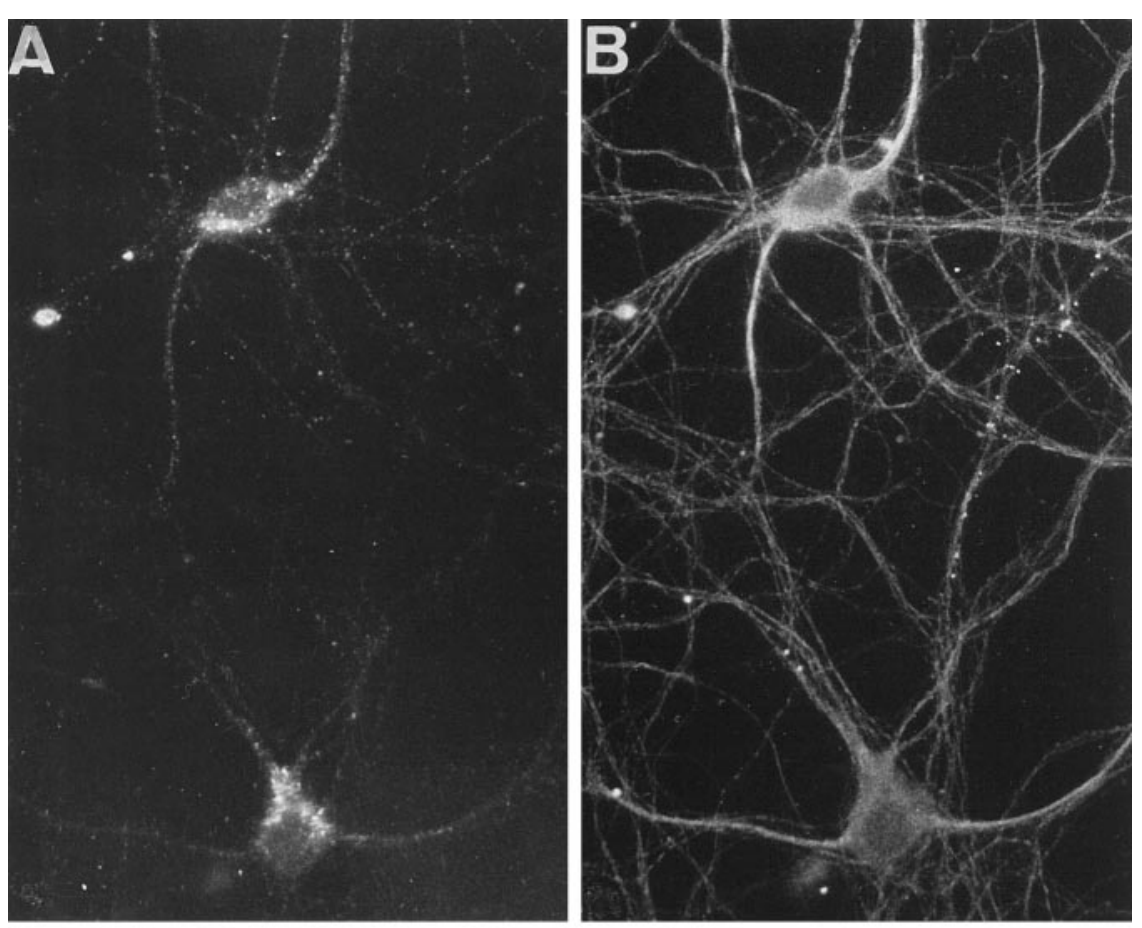

Figure 4. TI-VAMP/VAMP7 enriches in dendrites in mature hippocampal neuron. Rat hippocampal neurons were differentiated in primary culture and stained at 14 div. TI-VAMP/VAMP7 is present in neuronal cell bodies, and it is concentrated in a subpopulation of processes that correspond to dendrites. $A, B$, Double immunostaining for TI-VAMP/VAMP7 $(A)$ and microtubules $(B)$. Note that TI-VAMP/VAMP7 immunoreactivity is enriched in a subset of short and tapered processes (putative dendrites). $C, D$, Double immunostaining for TI-VAMP/VAMP7 $(C)$ and MAP2 $(D)$. Note that TI-VAMP/VAMP7 concentrates in MAP2-positive cell extensions. Scale bar: $A$, $B, 28 \mu \mathrm{m} ; C, D, 21 \mu \mathrm{m}$.
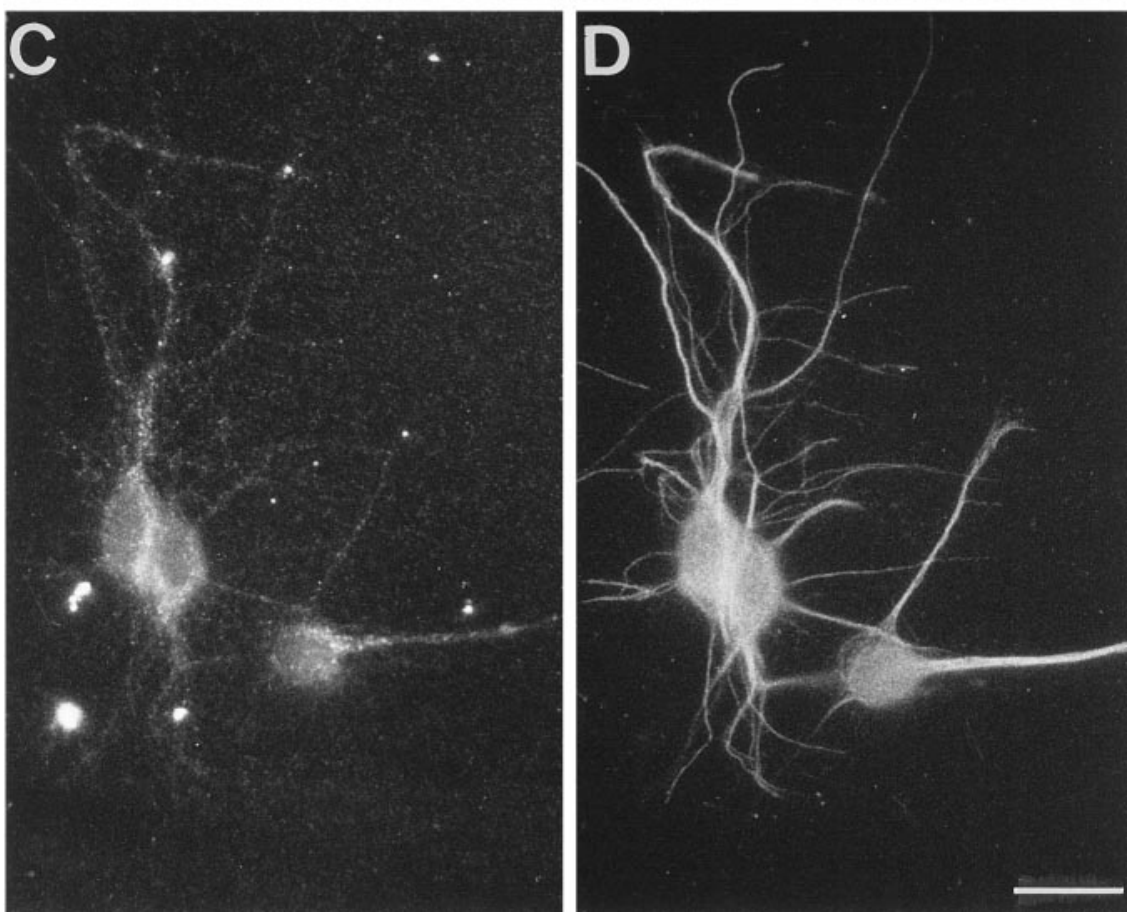

ment as synaptobrevin 2 or whether its subcellular localization in neurons was rather compatible with a role of this SNARE in neurite outgrowth, a process that is insensitive to TeNT and thus does not require synaptobrevin 2 .

\section{MATERIALS AND METHODS}

Antibodies. Affinity-purified serum directed against TI-VAMP/VAMP7 (TG11 and TG16) were described previously (Galli et al., 1998; Lafont et al., 1999). Mouse monoclonal antibodies directed against chromogranin B (CgB) (219-6) (generous gift of Dr. W. Huttner, University of Heidelberg, Heidelberg, Germany), human transferrin (H68.4) (generous gift of Dr. I. Trowbridge, Salk Insitute, San Diego, CA), CD63 (generous gift of Dr. Siraganian, National Institutes of Health, Washington, DC), CTR433 (generous gift of Dr. Bornens, Institut Curie, Paris, France), synaptic vesicle (SV) 2 (C110H4) (generous gift of Dr. Buckley, Harvard Medical School, Boston, MA), TGN38 (2F7.1) (generous gift from Dr. G. Banting, University of Bristol, Bristol, UK), early endosomal antigen 1 (EEA1) (Transduction Laboratories, Lexington, KY), microtubuleassociated protein 2 (MAP2) (Boehringer Mannheim, Mannheim, FRG), protein disulfide isomerase (PDI, 1D3) (Stressgen, Victoria, British Columbia, Canada), Thy1.1 (OX-7) (Chemicon, Temecula, CA), $\beta$-tubulin (Amersham Life Sciences, Buckinghamshire, UK), synaptobrevin 2 (C169.1), synaptotagmin 1 (C141.1), and rabbit polyclonal antibody against synaptophysin (p38) have been described previously. Affinity-purified Cy2, FITC, tetramethylrhodamine isothiocyanate, or Texas Red-coupled goat anti-rabbit and anti-mouse immunoglobulins were purchased from Jackson ImmunoResearch (West Grove, PA). Texas Red-coupled bovine serum albumin (BSA) was from Molecular Probes (Eugene, OR). 

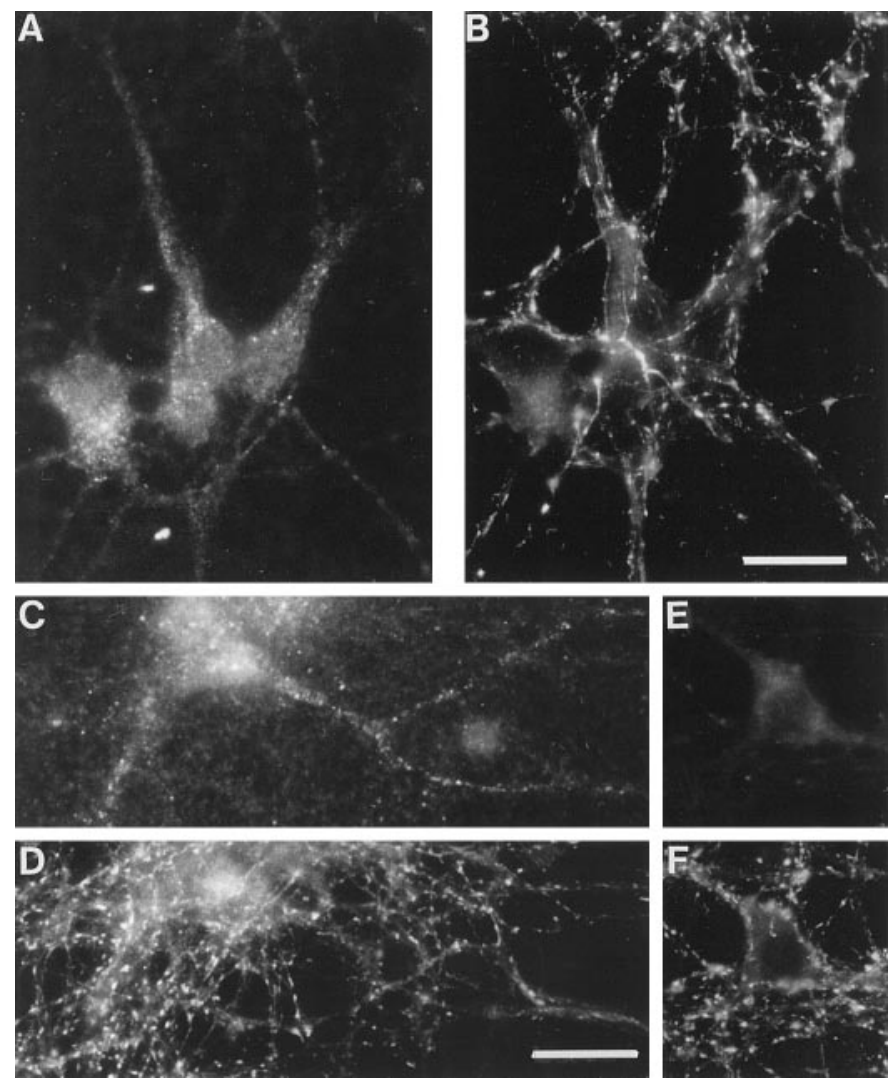

Figure 5. TI-VAMP/VAMP7 does not concentrate in nerve terminals in mature hippocampal neuron. Rat hippocampal neurons were differentiated in primary culture and stained at $14 \operatorname{div} . A, B$, Double immunostaining for TI-VAMP/VAMP7 $(A)$ and synaptobrevin $2(B)$. Note that TI-VAMP/VAMP7 immunoreactivity does not coincide with synaptobrevin 2 but is sometimes adjacent. $C, D$, Double immunostaining for TI-VAMP/VAMP7 $(C)$ and synaptotagmin $1(D)$ in hippocampal neurons that had been treated with TeNT. TeNT induces the loss of synaptobrevin 2 staining $(E)$ but not synaptophysin $(F)$. Note that TeNT has no effect on TI-VAMP/VAMP7 subcellular localization. Scale bars: $A, B, 42$ $\mu \mathrm{m} ; C-F, 36 \mu \mathrm{m}$.

Immunohistochemistry. Paraffin coronal sections of rat brain were stained with TG16 as described previously (Hsu et al., 1981). Digital pictures were obtained on a DMR HC microscope (Leica, Solms, Germany) equipped with a tri-CCD color video camera Power HAD (Sony, Tokyo, Japan).

Immunolabeling of frozen rat brain sections was performed as described previously (Takei et al., 1992). PC12 cells were cultured on collagen-coated glass coverslips for 4-5 d in the absence of nerve growth factor (NGF) or for $7 \mathrm{~d}$ in the presence of $50 \mathrm{ng} / \mathrm{ml} \mathrm{NGF}$. To identify late endocytic compartments, including lysosomes, NGF differentiated PC12 cells were starved for $30 \mathrm{~min}$ in serum-free medium, in the presence of NGF. The cells were then incubated in the same medium containing 5 $\mathrm{mg} / \mathrm{ml}$ Texas Red-coupled BSA for $2 \mathrm{hr}$ at $37^{\circ} \mathrm{C}$, and the fluid phase marker was then chased for $15 \mathrm{~min}$ at $37^{\circ} \mathrm{C}$ (Raposo et al., 1997). The cells were then processed for immunofluorescence as described previously (Chilcote et al., 1995). Confocal laser scanning microscopy was performed using a Leica TCS microscope. The images were assembled without modification using Adobe Photoshop and Adobe Illustrator (Adobe Systems, San Jose, CA).

Hippocampal cell cultures. Primary neuronal cultures were prepared from the hippocampi of 18-d-old fetal rats (Banker and Cowan, 1977; Bartlett and Banker, 1984) as described previously (Matteoli et al., 1996). For experimental treatments, neuronal cultures were exposed to $10 \mathrm{~nm}$ TeNT in the presence of $55 \mathrm{~mm} \mathrm{KCl}$ for $5 \mathrm{~min}$, thoroughly washed, and maintained in regular medium at $37^{\circ} \mathrm{C}$ for $2 \mathrm{hr}$ (Matteoli et al., 1996). After the incubation, neurons were fixed and double stained for MAP2, synaptobrevin 2, synaptophysin or synaptotagmin 1, and TI-VAMP/ VAMP7 or synaptophysin as indicated.
Immunogold labeling on ultrathin cryosections. PC12 cells were fixed with $2 \%$ paraformaldehyde in $0.1 \mathrm{~m}$ phosphate buffer, $\mathrm{pH} 7.4$, for $1 \mathrm{hr}$ at room temperature and processed for ultracryomicrotomy as described previously (Raposo et al., 1997). Ultrathin cryosections were collected using a mixture of $2.3 \mathrm{M}$ sucrose and methylcellulose $(\mathrm{v} / \mathrm{v})$ and were immunogold-labeled with antibodies against TI-VAMP/VAMP7 (TG16) and protein A gold conjugates (PAG 10; Department of Cell Biology, Utrecht University Medical School, Utrecht, Netherlands) (Raposo et al., 1997). No labeling was observed with protein A gold alone or nonimmune serum and protein A gold. Identification of intracellular membrane compartments of PC12 cells was performed as described previously (Steegmaier et al., 1999). Quantitation of TI-VAMP/VAMP7-positive compartments was performed by counting under the electron microscope the number of gold particles labeling vesicles, tubules, large dense core vesicles (LDCVs), or Golgi membranes in 22 cell profiles.

Subcellular fractionation. Rat brain SVs were prepared as described previously (Hell and Jahn, 1994). Bovine adrenal medulla homogenate was fractionated on a continuous sucrose gradient as described previously (Walch-Solimena et al., 1993).

\section{RESULTS}

\section{Subcellular localization of TI-VAMP/VAMP7 in the brain} We first examined the expression of TI-VAMP/VAMP7 in the rat brain. Immunohistochemical experiments on paraffin sections of the rat brain showed that the protein is present throughout the gray matter of the adult rat brain (Fig. $1 A$ ). The highest levels were observed in the molecular layer of the cerebellum, but all of the structures of the forebrain and the hindbrain showed expression of the protein. The distribution of TI-VAMP/VAMP7 immunoreactivity in the gray matter of some of the major parts of the encephalon is described below. At high magnification, we found a high level of the protein in the cell bodies of neurons, particularly in pyramidal cells of the hippocampus of the CA1 region, reticular cells, and Purkinje cells (Fig. $1 \mathrm{~A}$, bottom panels). The staining appeared as punctate structures, which are highly concentrated in the cell bodies but also extended into the proximal portions of the dendrites. The very intense staining observed in the stratum radiatum could be attributable to small dendrites or to nerve terminals. A lack of staining of nerve terminals was more evident in the case of reticular cells in which the staining was restricted to the cell bodies and dendrites (Fig. 1A). To confirm this result, we performed double immunofluorescence with anti-TI-VAMP/VAMP7 combined with anti-SV2 antibodies. Figure $1 B$ shows typical stainings observed by confocal microscopy in the deep nuclei of the cerebellum. TI-VAMP/ VAMP7 immunoreactivity corresponded to punctate structures in the somatodendritic region but was absent from nerve terminals (SV2-positive structures).

To further demonstrate that TI-VAMP/VAMP7 did not correspond to a typical SV protein, we purified SVs from a rat brain homogenate. Figure $2 A$ shows that TI-VAMP/VAMP7 did not enrich in LP2 or in PIII fractions, PIII corresponding to virtually pure SVs, whereas synaptobrevin 2, as expected, greatly enriched in these fractions (Hell and Jahn, 1994). The other main calciumregulated secretory vesicle found at high concentration in neurons and neuroendocrine cells is the secretory granule or LDCV. Because of their very high density, LDCVs migrate in heavy fractions of $\sim 2 \mathrm{M}$ sucrose density in isopycnic gradients. We have searched for the presence of TI-VAMP/VAMP7 in a sucrose gradient of bovine adrenal medulla postnuclear supernatant. We found that TI-VAMP/VAMP7 is present mainly in light fractions and peaks in fractions corresponding to $1 \mathrm{M}$ sucrose. The profile of TI-VAMP/VAMP7 is similar to that of transferrin receptor. We were able to confirm the occurrence of synaptotagmin 1 and synaptobrevin 2 in LDCVs because both proteins concentrated in 

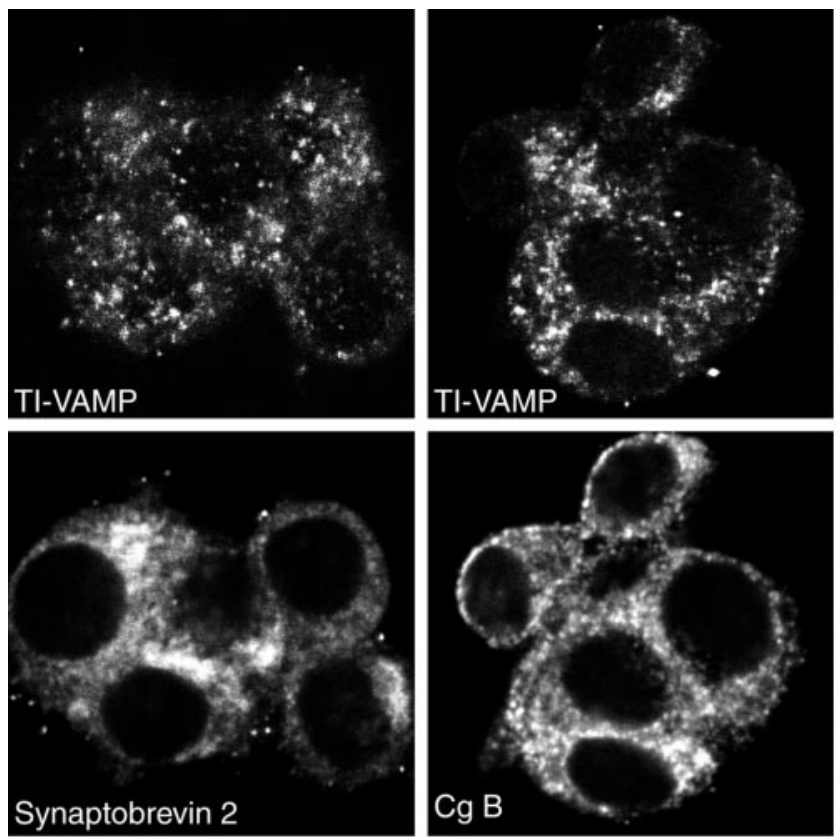

$+\mathrm{NGF}$
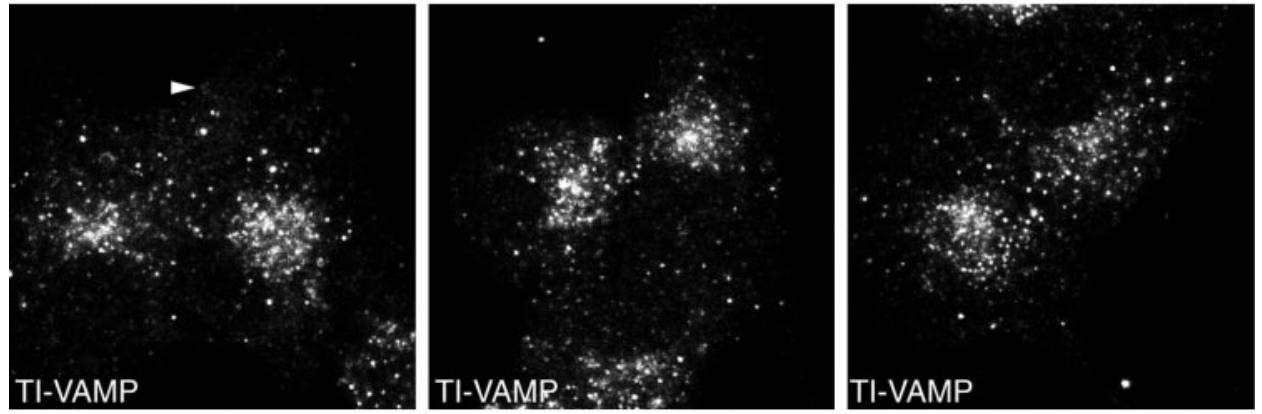

gen-coated glass and treated with (bottom panels) or without (top panels) $50 \mathrm{ng} / \mathrm{ml}$ NGF for $7 \mathrm{~d}$. The cells were then stained for TI-VAMP/VAMP7 and several membrane markers and observed by confocal microscopy. We found that TI-VAMP/VAMP7 does not colocalize with synaptobrevin 2 or chromogranin B but overlaps to a low extent with CD63, a protein known to recycle between lysosomes or granules and the plasma membrane (arrows in top right micrographs). TI-VAMP/VAMP7 does not enrich in varicosities (arrowheads in bottom left micrographs) in which synaptobrevin 2 concentrates after NGF treatment. Scale bars, $5 \mu \mathrm{m}$.
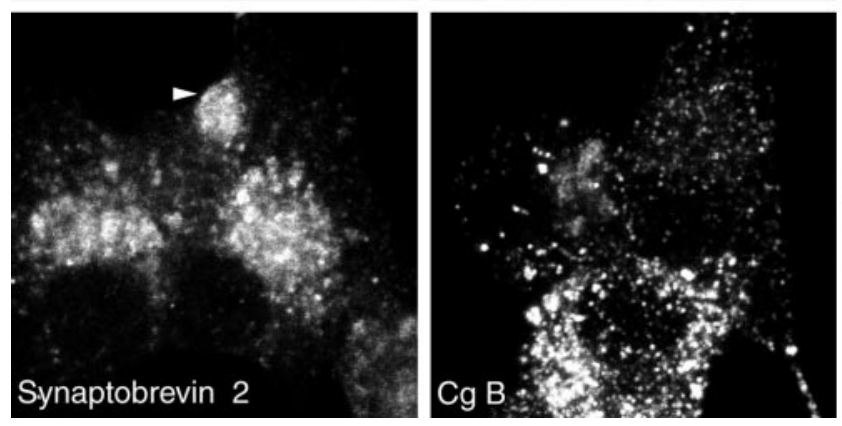

a second peak at the bottom of the gradient, corresponding to 1.9-2 M sucrose, although the bulk of synaptobrevin 2 appears in light fractions (Fig. 2B). Altogether, these results demonstrated that TI-VAMP/VAMP7 has an original distribution in the rat brain, different from that of synaptobrevin 2, and does not enrich in SVs or LDCVs.

\section{TI-VAMP/VAMP7 is targeted to dendrite and axonal outgrowths in developing neurons}

It was shown recently that treatment with TeNT or BoNT/B had no effects on neurite extension and synaptogenesis of neurons in primary culture, although it blocked neurotransmitter release (OsenSand et al., 1996). Therefore, we have studied the subcellular localization of TI-VAMP/VAMP7 during the course of maturation of hippocampal neurons in primary culture. At 2 days in vitro (div), TI-VAMP/VAMP7 was strongly concentrated in the axon outgrowth, particularly in the leading edge of the growth cone, a region devoid of synaptobrevin 2 (Fig. 3A, arrows). TIVAMP/VAMP7 was also found in hot spots along the axon, in the cell body, and in the growing dendrites. At this stage, the distribution of synaptobrevin 2 was not yet fully polarized; most of the immunoreactivity was seen in the axon and the axon outgrowth, but punctate structures were still present in the somatodendritic region. At 7 div, TI-VAMP/VAMP7 immunoreactivity concentrated into the cell bodies and in the dendrites, whereas synaptobrevin 2 was greatly enriched in nerve terminals (Fig. $3 B$ ). In developing neurons observed at $7 \mathrm{div}$, TI-VAMP/VAMP7 was also found at high concentrations in the leading edge of dendrites, which are devoid of synaptobrevin 2 (Fig. 3B, arrowheads). At 14 div, the neurons were fully differentiated, and synaptogenesis was accomplished. At this stage, most of TI-VAMP/VAMP7 immu- 

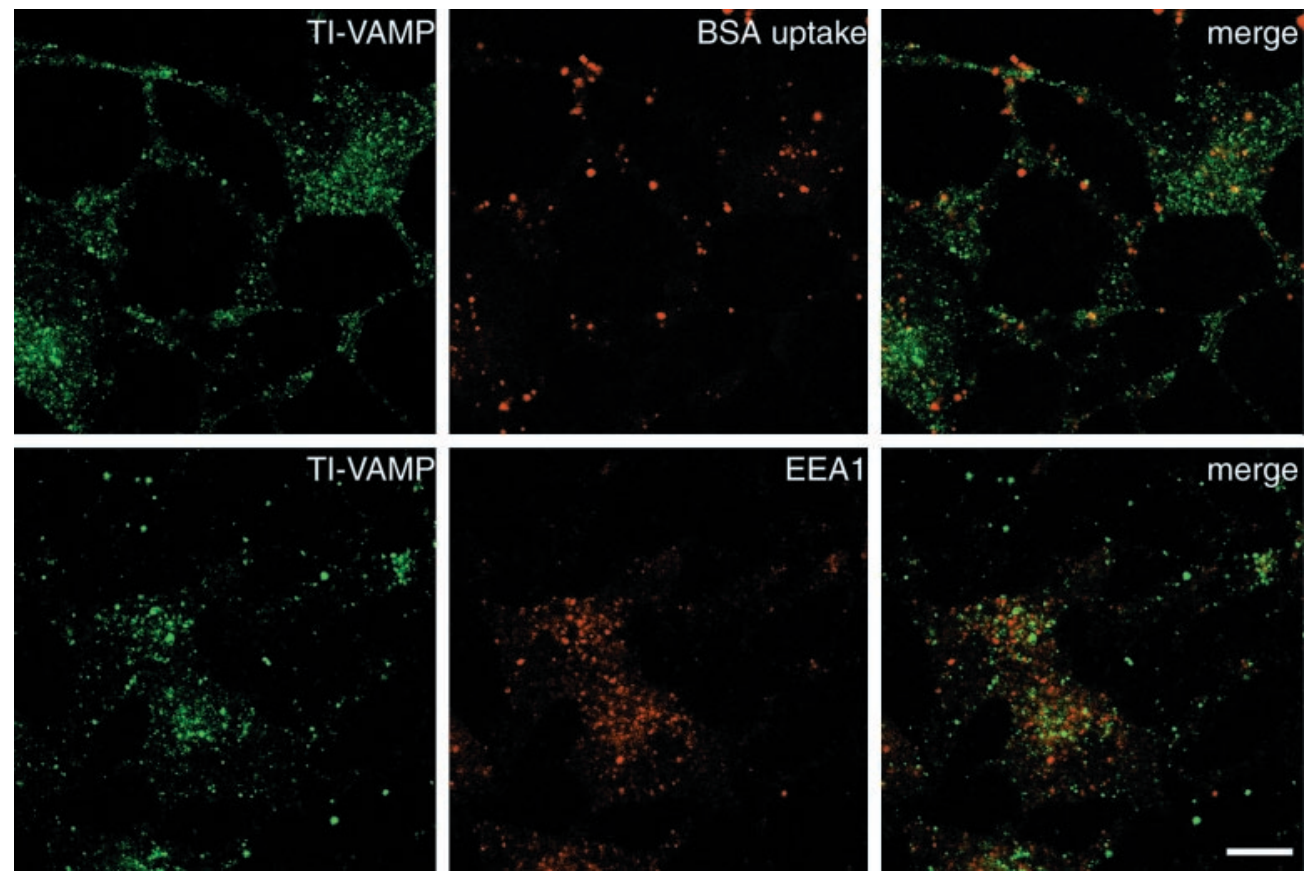

Figure 7. TI-VAMP/VAMP7 does not localize into endocytic compartments in NGF-treated PC12 cells. PC12 cells were grown on collagen-coated glass and treated with $50 \mathrm{ng} / \mathrm{ml} \mathrm{NGF}$ for $6 \mathrm{~d}$. Top row, The cells were starved for 30 min in serum-free medium in the presence of NGF and then incubated in the same medium containing $5 \mathrm{mg} / \mathrm{ml}$ Texas Red-coupled BSA for $2 \mathrm{hr}$, and the fluid phase marker was subsequently chased in serum-free medium for $15 \mathrm{~min}$. The cells were then stained for TI-VAMP/ VAMP7 and observed by confocal microscopy. Note that TI-VAMP/VAMP7 does not colocalize with the BSApositive endocytic structures. Bottom row, The cells were stained for TI-VAMP/ VAMP7 and the early endosome marker EEA1 and observed by confocal microscopy. TI-VAMP/VAMP7 does not colocalize with EEA1. In both cases, note the great differences in the pattern of TIVAMP staining and the localization of endocytic structures. Scale bar, $10 \mu \mathrm{m}$. noreactivity was present in neuronal cell bodies and in a subpopulation of processes as seen after double labeling with an antibody directed against $\beta$-tubulin (Fig. $4 A, B$ ). The bulk of TI-VAMP/ VAMP7 staining was concentrated in extensions that were also MAP2-positive (Fig. 4C,D) and should therefore be within the somatodendritic region. Figure 5 presents micrographs of mature neurons that were treated with or without TeNT. TI-VAMP/ VAMP7 immunoreactivity did not overlap with that of synaptobrevin 2 (Fig. $5 A, B$ ) in untreated neurons, and its distribution was not affected by TeNT treatment (Fig. 5, compare $A, C$ ) as expected because TI-VAMP/VAMP7 is insensitive to TeNT (Galli et al., 1998). Synaptobrevin 2 and synaptotagmin 1 immunoreactivities were observed in varicosities and nerve terminals and were, in general, undetectable in cell bodies and dendrites (Fig. 5B,D, respectively). TeNT treatment was effective because it decreased synaptobrevin 2 immunoreactivity to background level (Fig. $6 E$ ) but did not affect synaptophysin (Fig. $5 F$ ). Noteworthy, TI-VAMP/VAMP7 "hot spots" were often visible along the dendrites in regions that were adjacent to nerve terminals (Fig. 5, compare $A, B$ ). It is therefore likely that TI-VAMP/ VAMP7 could enrich in postsynaptic densities.

\section{Original distribution of TI-VAMP/VAMP7 in PC12 cells}

To further characterize the intracellular compartment to which TI-VAMP/VAMP7 localized, we have conducted a large series of double immunofluorescence experiments in PC12 cells that had been treated with or without NGF. This cell line has neuronal properties, including calcium-dependent secretion, and NGF induces the formation of neurites with varicosities in which synaptic-like microvesicles and LDCVs are concentrated. We found that TI-VAMP/VAMP7 does not colocalize significantly with an endoplasmic reticulum (ER) marker (PDI), Golgi markers (CTR433, TGN38), Thy1.1, a glypiated protein that we found mainly at the plasma membrane, synaptobrevin 2, and $\mathrm{CgB}$ (data not shown; Figs. 6, 7). In particular, we have confirmed the presence of synaptobrevin 2 in endosomes concentrated in the perinuclear region, SVs, and LDCVs in PC12 cells and its great enrichment into varicosities and neurite extensions upon NGF differentiation. TI-VAMP/VAMP7 immunoreactivity appeared as a punctate staining in the cytoplasm that did not concentrate in either the perinuclear region or varicosities upon NGF treatment (Fig. 6, arrowhead in bottom right micrographs). On the contrary, $\mathrm{CgB}$ immunoreactivity was often concentrated very close to the plasma membrane and also enriched in varicosities after NGF treatment (Fig. 6). The only marker that we found to partially overlap with TI-VAMP/VAMP7 was CD63 (Fig. 6). Figure 6 shows that TI-VAMP/VAMP7 and CD63 had a similar pattern of distribution, and, in general, they enriched in the same areas of the cell (Fig. 6, arrow in top right micrographs). Both proteins were present at low levels in NGF-induced neuritic extensions, although they did not enrich in varicosities (Fig. 6; data not shown). Advani et al. (1998) have shown recently that TI-VAMP/VAMP7 colocalizes with a late endosome and lysosomal marker upon overexpression of an epitope-tagged form of this SNARE in rat kidney cells. We have found that this is also the case in HeLa cells when TI-VAMP/VAMP7 is overexpressed, but we found a lack of colocalization of the endogeneous SNARE with lysosomalassociated membrane protein 1 (data not shown). To show that endogeneous TI-VAMP does not localize into late endosomes and lysosomes in neuronal cells, we have incubated PC12 cells with Texas Red-coupled BSA for $2 \mathrm{hr}$ and further chased the fluid phase marker into late endocytic structures for additional $15 \mathrm{~min}$ as described previously (Raposo et al., 1997). Figure 7 shows that the immunoreactivity of TI-VAMP/VAMP7 did not correspond to the structures that had incorporated BSA. Double staining of TI-VAMP and early endosomal markers (transferrin receptor, EEA1) (Patki et al., 1997) showed a lack of colocalization (data not shown; Fig. 8) as we had already observed in polarized CaCo-2 cells (Galli et al., 1998).

\section{Identification of TI-VAMP/VAMP7 compartment by electron microscopy}

Finally, TI-VAMP/VAMP7 compartment was studied at the ultrastructural level by immunogold labeling of ultrathin cryosections of PC12 cells. Quantitation of the intracellular labeling for TI-VAMP/VAMP7 on 22 cell profiles and on the basis of 268 
Figure 8. TI-VAMP/VAMP7 is present in tubules and vesicles in PC12 cells. Ultrathin cryosections of PC12 cells were labeled with antibodies directed against TIVAMP/VAMP7, followed by protein A coupled to 10 nm gold particles (PAG10). Labeling for TI-VAMP/ VAMP7 is detected mainly on the cytoplasmic side of vesicles and tubules (arrowheads), LDCVs, and occasionally in Golgi stacks. Note the labeling on a bud from LDCV (inset) and the lack of staining of lysosomes (open arrowhead indicates a labeled tubule nearby an unlabeled lysosome). Note that the top micrograph is particularly poor in LDCVs compared with the bottom micrograph. This is because of the fact that the distribution of LDCVs is not homogeneous within a PC12 cell in which these heavy organelles tend to enrich at the bottom of the cell. The distribution of gold particles of these micrographs qualitatively but not quantitatively represents the cell profiles that were used to quantitate the data expressed in Results. Scale bars, $104 \mathrm{~nm}$. PM, Plasma membrane; $M$, mitochondria, $G A$, Golgi apparatus; $L$, lysosome.

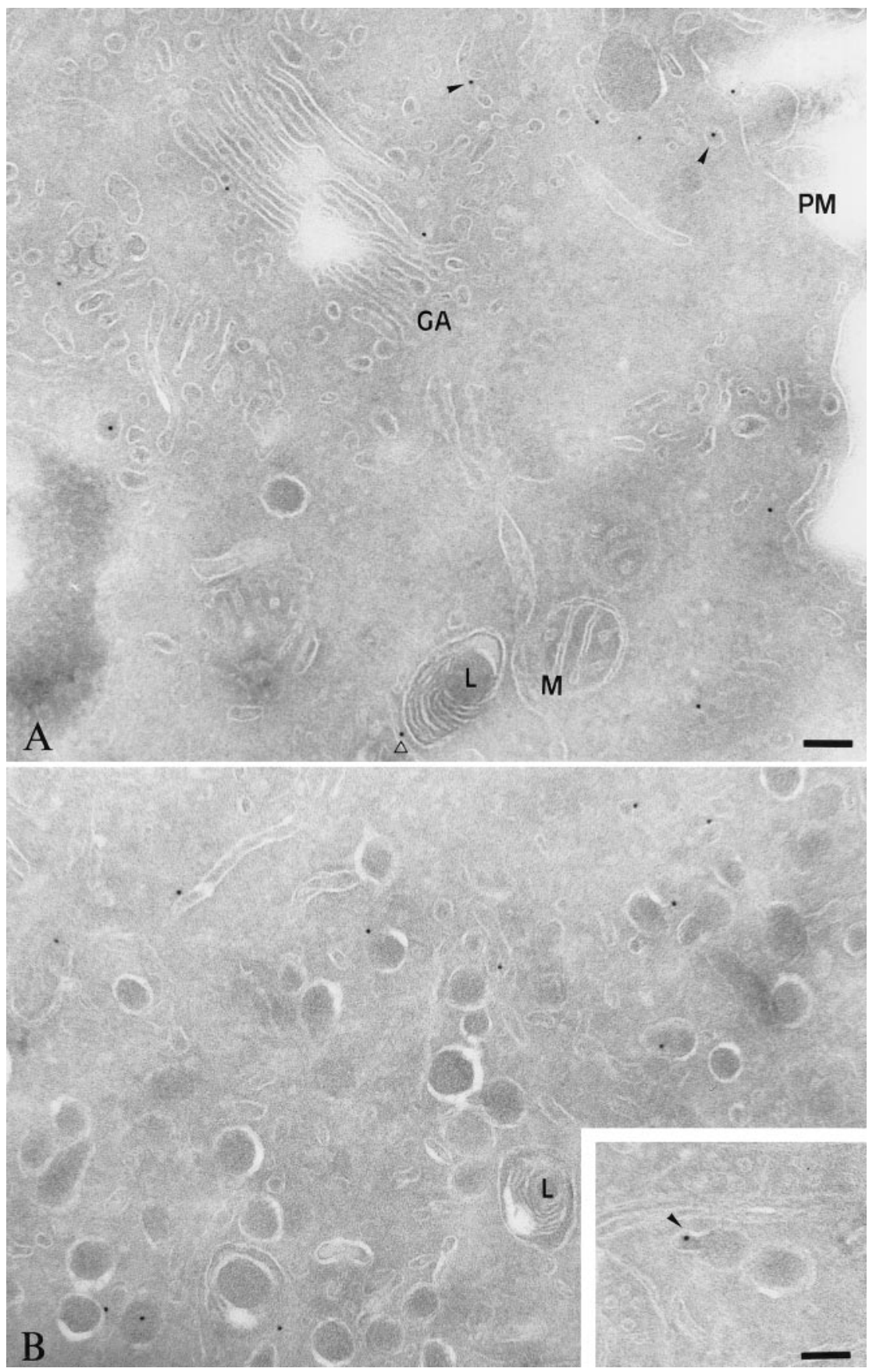

gold particles showed that TI-VAMP/VAMP7 immunoreactivity was restricted to tubulovesicular structures of $20-50 \mathrm{~nm}$ in diameter (60.8\% of the labeling), LDCVs (31.0\% of the labeling), and Golgi (8.2\% of the labeling). We did not observe staining of lysosomes. TI-VAMP/VAMP7 associated very rarely with a bud connected to a LDCV (Fig. 8, inset), a multi-vesicular body, or the plasma membrane (Fig. 8).

\section{DISCUSSION}

In the present study, we found that TI-VAMP/VAMP7 had a widespread distribution in the gray matter of the rat encephalon. TI-VAMP/VAMP7 localized in vesicular structures in axons and dendrites in immature neurons and scattered throughout the somatodendritic region only in mature neurons in primary cul- ture. We did not find any significant colocalization with ER, Golgi, SV, or LDCV markers by confocal microscopy. Electron microscopy analysis of immunogold-labeled sections of PC12 cells indicated that TI-VAMP/VAMP7 localized in vesicles and tubules of 20-50 nm in diameter. We have also found labeling of LDCVs and of buds on LDCVs. Subcellular fractionation of bovine adrenal medulla showed that TI-VAMP/VAMP7 does not significantly enrich in LDCVs. Moreover, we have shown previously that TeNT almost completely blocks calciumdependent secretion from LDCVs (Chilcote et al., 1995). Therefore, it is likely that TI-VAMP/VAMP7 is not a typical LDCV marker and does not play a major role in exocytosis of LDCVs but could rather be transiently associated with these organelles. Double immunofluorescence studies in PC12 cells showed that 
TI-VAMP/VAMP7-positive structures partially overlap with CD63, a protein that is transported to the plasma membrane (Dell'Angelica et al., 1999) in which it is involved in integrindependent adhesion and can also be found in granules and lysosomes (Berditchevski et al., 1995; Maecker et al., 1997). The group of R. Scheller has shown that, when TI-VAMP/VAMP7 was overexpressed in fibroblasts, the immunoreactivity was mostly found in lysosomes (Advani et al., 1998). They proposed that TI-VAMP/VAMP7 could mediate fusion with lysosomes (Advani et al., 1998). It should be noted however, that syntaxin 3, a t-SNARE that we have shown to form a complex with TI$\mathrm{VAMP} / \mathrm{VAMP} 7$ in vivo in $\mathrm{CaCo}-2$ cells, can also be found in lysosomes when it is overexpressed in MDCK cells (Low et al., 1996), whereas the endogeneous syntaxin 3 is restricted to the apical plasma membrane (Galli et al., 1998). Thus, it is likely that the lysosomal localization of transiently expressed TI-VAMP/ VAMP7 was the result of the very high level of expression. We do not believe that TI-VAMP/VAMP7 mediates primarily transport to lysosomes because (1) the immunoreactivity for endogeneous TI-VAMP/VAMP7 was not found to be associated with lysosomes by EM (this study) in PC12 cells or in CaCo-2 (Galli et al., 1998) or HeLa cells by confocal microscopy (data not shown), and (2) TI-VAMP/VAMP7 interacts in vivo with t-SNAREs of the apical plasma membrane (Galli et al., 1998) and is involved in transport of HA to the apical plasma membrane in MDCK cells (Lafont et al., 1999). On the contrary, we propose that TIVAMP/VAMP7 mediates NT-insensitive fusion of post-Golgi vesicles with the plasma membrane in both neurons and epithelial cells. Moreover, we have found recently that TI-VAMP/VAMP7 is associated with rafts in epithelial cells (Lafont et al., 1999). Altogether, these data suggest that TI-VAMP/VAMP7 may define a novel membrane compartment. This compartment could correspond in part to immature secretory granule-derived vesicles (IDVs) because our EM data show that a low percentage of LDCVs are positive for TI-VAMP/VAMP7. IDVs have been proposed to mediate a constitutive-like secretion in neurons and neuroendocrine cells (Dittie et al., 1996) (for review, see Thiele et al., 1997), but their precise function is not yet defined.

In hippocampal neurons developing in vitro, TI-VAMP/ VAMP7 was localized into the growing axon and dendrites, in particular in the leading edge of the axon and dendrite outgrowths and in hot spots along the axon. Interestingly, proteins of the exocyst complex that are supposed to specify sites of exocytosis have recently been localized to the same compartments in developing neurons (Hazuka et al., 1999). TeNT has been found to have no effect on dendrite and axonal outgrowth in cortical neurons in primary culture (OsenSand et al., 1996). We propose that TI-VAMP/VAMP7 could mediate, at least in part, axon and neurite outgrowth. In mature neurons and in the adult brain, TI-VAMP/VAMP7 was not detected in nerve terminals but was found in dendrites in which it could be involved in a specialized secretory pathway or dendritic membrane expansion. Such processes could be important in the transport of postsynaptic receptors and other constituents of the dendritic plasma membrane but could also be involved in dendritic release of neurotransmitters, including catecholamines (Cheramy et al., 1981; Jaffe et al., 1998) or other factors. They could play a role in the dendritic morphogenetic changes that are seen after intense synaptic stimulation (MaleticSavatic et al., 1999). Although the molecular mechanism of SV recycling in the nerve terminal of mature neurons has been extremely well documented, very little is known about the molecules involved in the membrane fusion events leading to neurite outgrowth and exocytosis in dendrites. A calcium-evoked TeNTsensitive dendritic exocytosis has recently been observed using the dye FM 1-43 (MaleticSavatic and Malinow, 1998; MaleticSavatic et al., 1998). A postsynaptic role of NSF and SNAPs has also been described in long-term potentiation (Lledo et al., 1998), but it is not clear whether or not the underlying molecular events depend on an effect on membrane fusion (Nishimune et al., 1998; Osten et al., 1998; Noel et al., 1999). Identification of TI-VAMP/ VAMP7 in axonal and dendritic outgrowths and in dendrites of mature neurons opens the way to a better understanding of the molecular mechanism and regulation of membrane expansion in neurites and dendritic exocytotic pathways. Future goals include the identification of the cargo proteins transported in TI-VAMP/ VAMP7s vesicles, the t-SNAREs that partner in vivo in neurons with TI-VAMP/VAMP7, and the physiological properties of TIVAMP/VAMP7-mediated membrane fusion events.

\section{REFERENCES}

Advani RJ, Bae HR, Bock JB, Chao DS, Doung YC, Prekeris R, Yoo JS, Scheller RH (1998) Seven novel mammalian SNARE proteins localize to distinct membrane compartments. J Biol Chem 273:10317-10324.

Banker GA, Cowan WM (1977) Rat hippocampal neurons in dispersed cell culture. Brain Res 126:397-425.

Bartlett WP, Banker GA (1984) An electron microscopic study of the development of axons and dendrites by hippocampal neurons in culture. I. Cells which develop without intercellular contacts. J Neurosci 4:1944-1953.

Berditchevski F, Bazzoni G, Hemler ME (1995) Specific association of CD63 with the VLA-3 and VLA-6 integrins. J Biol Chem 270:17784-17790.

Bock JB, Scheller RH (1997) Protein transport-a fusion of new ideas. Nature 387:133-135.

Chapron J, Vaillier J, Koenig J, de la Porte S, Bizzini B (1991) The effect of tetanus toxin on in vitro synaptogenesis. Neurosci Lett 121:21-24.

Cheramy A, Leviel V, Glowinski J (1981) Dendritic release of dopamine in the substantia nigra. Nature 289:537-542.

Chilcote TJ, Galli T, Mundigl O, Edelmann L, McPherson PS, Takei K, De Camilli P (1995) Cellubrevin and synaptobrevins: similar subcellular localization and biochemical properties in PC12 cells. J Cell Biol 129:219-231.

D'Esposito M, Ciccodicola A, Gianfrancesco F, Esposito T, Flagiello L, Mazzarella R, Schlessinger D, D’Urso M (1996) A synaptobrevin-like gene in the $\mathrm{Xq} 28$ pseudoautosomal region undergoes $\mathrm{X}$ inactivation. Nat Genet 13:227-229.

Dell'Angelica EC, Shotelersuk V, Aguilar RC, Gahl WA, Bonifacino JS (1999) Altered trafficking of lysosomal proteins in Hermansky-Pudlak syndrome due to mutations in the beta $3 \mathrm{~A}$ subunit of the AP-3 adaptor. Mol Cell 3:11-21.

Dittie AS, Hajibagheri N, Tooze SA (1996) The AP-1 adaptor complex binds to immature secretory granules from PC12 cells, and is regulated by ADP-ribosylation factor. J Cell Biol 132:523-536.

Edwardson JM (1998) Membrane fusion: all done with SNAREpins? Curr Biol 8:R390-R393.

Fasshauer D, Sutton RB, Brunger AT, Jahn R (1998) Conserved structural features of the synaptic fusion complex: SNARE proteins reclassified as Q- and R-SNAREs. Proc Natl Acad Sci USA 95:15781-15786.

Fasshauer D, Antonin W, Margittai M, Pabst S, Jahn R (1999) Mixed and non-cognate SNARE complexes. Characterization of assembly and biophysical properties. J Biol Chem 274:15440-15446.

Fassio A, Sala R, Bonanno G, Marchi M, Raiteri M (1999) Evidence for calcium-dependent vesicular transmitter release insensitive to tetanus toxin and botulinum toxin type F. Neuroscience 90:893-902.

Galli T, Chilcote T, Mundigl O, Binz T, Niemann H, De Camilli P (1994) Tetanus toxin-mediated cleavage of cellubrevin impairs exocytosis of transferrin receptor-containing vesicles in $\mathrm{CHO}$ cells. J Cell Biol 125:1015-1024.

Galli T, Garcia EP, Mundigl O, Chilcote TJ, De Camilli P (1995) v- and t-SNAREs in neuronal exocytosis: a need for additional components to define sites of release. Neuropharmacology 34:1351-1360.

Galli T, Zahraoui A, Vaidyanathan VV, Raposo G, Tian JM, Karin M, Niemann H, Louvard D (1998) A novel tetanus neurotoxin-insensitive 
vesicle-associated membrane protein in SNARE complexes of the apical plasma membrane of epithelial cells. Mol Biol Cell 9:1437-1448.

Grote E, Hao JC, Bennett MK, Kelly RB (1995) A targeting signal in VAMP regulating transport to synaptic vesicles. Cell 81:581-589.

Hay JC, Scheller RH (1997) SNAREs and NSF in targeted membrane fusion. Curr Opin Cell Biol 9:505-512.

Hazuka CD, Foletti DL, Hsu SC, Kee Y, Hopf FW, Scheller RH (1999) The sec6/8 complex is located at neurite outgrowth and axonal synapseassembly domains. J Neurosci 19:1324-1334.

Hell JW, Jahn R (1994) Preparation of synaptic vesicles from mammalian brain. In: Cell biology: a laboratory handbook, Ed 2, pp 567-574.

Hsu S-M, Raine L, Fanger H (1981) Use of avidin-biotin-peroxydase complex $(\mathrm{ABC})$ in immunoperoxydase techniques: a comparison between $\mathrm{ABC}$ and unlabeled antibody (PAP) procedures. J Histochem Cytochem 29:577-580.

Igarashi M, Kozaki S, Terakawa S, Kawano S, Ide C, Komiya Y (1996) Growth cone collapse and inhibition of neurite growth by Botulinum neurotoxin C1: a t-SNARE is involved in axonal growth. J Cell Biol 134:205-215.

Ikonen E, Tagaya M, Ullrich O, Montecucco C, Simons K (1995) Different requirements for NSF, SNAP, and rab proteins in apical and basolateral transport in MDCK cells. Cell 81:571-580.

Jaffe EH, Marty A, Schulte A, Chow RH (1998) Extrasynaptic vesicular transmitter release from the somata of substantia nigra neurons in rat midbrain slices. J Neurosci 18:3548-3553.

Jahn R, Sudhof TC (1999) Membrane fusion and exocytosis. Annu Rev Biochem, in press.

Johannes L, Galli T (1998) Exocytosis: SNAREs drum up. Eur J Neurosci 10:415-422.

Lafont F, Verkade P, Galli T, Wimmer C, Louvard D, Simons K (1999) Raft-association of SNAREs acting in apical trafficking in MDCK cells. Proc Natl Acad Sci USA 96:3734-3738.

Lledo PM, Zhang X, Sudhof TC, Malenka RC, Nicoll RA (1998) Postsynaptic membrane fusion and long-term potentiation. Science 279:399-403.

Low SH, Chapin SJ, Weimbs T, Komuves LG, Bennett MK, Mostov KE (1996) Differential localization of syntaxin isoforms in polarized Madin-Darby canine kidney cells. Mol Biol Cell 7:2007-2018.

Maecker HT, Todd SC, Levy S (1997) The tetraspanin superfamily: molecular facilitators. FASEB J 11:428-442.

MaleticSavatic M, Malinow R (1998) Calcium-evoked dendritic exocytosis in cultured hippocampal neurons. I. Trans-Golgi network-derived organelles undergo regulated exocytosis. J Neurosci 18:6803-6813.

MaleticSavatic M, Koothan T, Malinow R (1998) Calcium-evoked dendritic exocytosis in cultured hippocampal neurons. II. Mediation by calcium/calmodulin-dependent protein kinase II. J Neurosci 18:6814-6821.

MaleticSavatic M, Malinow R, Svoboda K (1999) Rapid dendritic morphogenesis in CA1 hippocampal dendrites induced by synaptic activity. Science 283:1923-1927.

Matteoli M, Verderio C, Rossetto O, Iezzi N, Coco S, Schiavo G, Montecucco C (1996) Synaptic vesicle endocytosis mediates the entry of tetanus neurotoxin into hippocampal neurons. Proc Natl Acad Sci USA 93:13310-13315.
Nishimune A, Isaac JTR, Molnar E, Noel J, Nash SR, Tagaya M, Collingridge GL, Nakanishi S, Henley JM (1998) NSF binding to GluR2 regulates synaptic transmission. Neuron 21:87-97.

Noel J, Ralph GS, Pickard L, Williams J, Molnar E, Uney JB, Collingridge GL, Henley JM (1999) Surface expression of AMPA receptors in hippocampal neurons is regulated by an NSF-dependent mechanism. Neuron 23:365-376.

OsenSand A, Staple JK, Naldi E, Schiavo G, Rossetto O, Petitpierre S, Malgaroli A, Montecucco C, Catsicas S (1996) Common and distinct fusion proteins in axonal growth and transmitter release. J Comp Neurol 367:222-234.

Osten P, Srivastava S, Inman GJ, Vilim FS, Khatri L, Lee LM, States BA, Einheber S, Milner TA, Hanson PI, Ziff EB (1998) The AMPA receptor GluR2 C terminus can mediate a reversible, ATP-dependent interaction with NSF and alpha- and beta-SNAPs. Neuron 21:99-110.

Patki V, Virbasius J, Lane WS, Toh BH, Shpetner HS, Corvera S (1997) Identification of an early endosomal protein regulated by phosphatidylinositol 3-kinase. Proc Natl Acad Sci USA 94:7326-7330.

Raposo G, Kleijmer KJ, Posthuma G, Slot JW, Geuze HJ (1997) Immunogold labeling of ultrathin cryosections: application in immunology. In: Handbook of experimental immunology (Herzenberg LA, Weir DM, Blackwell C, eds), pp 1-11. Malden, MA: Blackwell.

Regazzi R, Wollheim CB, Lang J, Theler JM, Rossetto O, Montecucco C, Sadoul K, Weller U, Palmer M, Thorens B (1995) VAMP-2 and cellubrevin are expressed in pancreatic cells and are essential for $\mathrm{Ca}^{2+}$ but not for GTP $\gamma$ S-induced insulin secretion. EMBO J 14:2723-2730.

Sellin LC, Molgo J, Tornquist K, Hansson B, Thesleff S (1996) On the possible origin of giant or slow-rising miniature end-plate potentials at the neuromuscular junction. Pflügers Arch 431:325-334.

Simons K, Ikonen E (1997) Functional rafts in cell membranes. Nature 387:569-572.

Steegmaier M, Klumperman J, Foletti DL, Yoo JS, Scheller RH (1999) Vesicle-associated membrane protein 4 is implicated in trans-Golgi network vesicle trafficking. Mol Biol Cell 10:1957-1972.

Takei K, Stukenbrok H, Metcalf A, Mignery GA, Sudhof TC, Volpe P, De Camilli P (1992) $\mathrm{Ca}^{2+}$ stores in Purkinje neurons: endoplasmic reticulum subcompartments demonstrated by the heterogeneous distribution of the InsP3 receptor, $\mathrm{Ca}^{2+}$-ATPase, and calsequestrin. J Neurosci 12:489-505.

Thiele C, Gerdes HH, Huttner WB (1997) Protein secretion: puzzling receptors. Curr Biol 7:R496-R500.

Von Mollard GF, Nothwehr SF, Stevens TH (1997) The yeast v-SNARE Vtilp mediates two vesicle transport pathways through interactions with the t-SNAREs Sed5p and Pep12p. J Cell Biol 137:1511-1524.

Walch-Solimena C, Takei K, Marek KL, Midyett K, Südhof TC, De Camilli P, Jahn R (1993) Synaptotagmin: a membrane constituent of neuropeptide-containing large dense-core vesicles. J Neurosci 13:3895-3903.

Weber T, Zemelman BV, McNew JA, Westermann B, Gmachl M, Parlati F, Sollner TH, Rothman JE (1998) SNAREpins: minimal machinery for membrane fusion. Cell 92:759-772.

Yang B, Gonzalez L, Prekeris R, Steegmaier M, Advani RJ, Scheller RH (1999) SNARE interactions are not selective-implications for membrane fusion specificity. J Biol Chem 274:5649-5653. 